\title{
LANDSCAPE HETEROGENEITY MAPPING FOR ACCESS TO TRIBAL HEALTH CARE IN NILGIRIS DISTRICT OF TAMIL NADU, INDIA
}

\author{
Brindha B and Prashanthi Devi M \\ Department of Environmental Management \\ Bharathidasan University \\ Tiruchirapalli - 620024 \\ Tamil Nadu, India \\ email:prashanthidevi@gmail.com
}

KEY WORDS: Tribal health, Landscape Mapping, GIS, Accessibility

\begin{abstract}
:
The Nilgiris district in Tamilnadu has a rich biodiversity in terms of flora, fauna and ethnic population. The district is basically a mountainous region, situated at an elevation of 2000 to 2,600 meters above MSL and constituting of several hill and Steep Mountain valleys. This region houses six tribes who are mainly forest dwellers and live in close settlements depending on the forest resources for their livelihood. The Tribes of Nilgiris have been diagnosed and monitored for Sickle cell Anemia which is a disease of major concern among these ethnic populations. This genetic disorder developed due to the sickling of Red Blood Cells has increased during the past few decades. The Tribes, as they live in close encounter with the forest regions and have strict social cultural barriers, face difficulty in availing treatment or counseling from the Sickle Cell Research Center (SCRC) and other NGOs like NAWA and AHWINI in the region. It was observed that many factors such as landscape terrain, climatic conditions and improper roads tend to hinder the access to appropriate health care. The SCRC in Gudalur region is a facility established to monitor the disease cases inspite of these influencing factors. On analyzing the year bound age wise classification among male and female patients, certain dropouts in cases were observed which may be due to inaccessible condition or migration of the patient.

In our study, Landscape heterogeneity mapping for different climatic seasons was done in ArcGIS 10.1. For this, contour and terrain maps, road networks and villages were prepared and factors that determine Terrain Difficulty were assessed. Vegetation mapping using IRS satellite images for the study region was attempted and associated with the landscape map. A risk analysis was proposed based on terrain difficulty and access to the nearest Health care Center. Based on this, the above factors alternate routes were suggested to access the difficult areas.
\end{abstract}

\subsection{Introduction}

Limited physical access to primary health care is a major factor contributing to the poor health of populations in developing countries, particularly in mountain areas with rugged topography, harsh climates and improper roads. Landscape connectivity can be broken down into structural components, as well as functional components. Structural connectivity refers to characteristics of the landscape such as habitat suitability, while functional connectivity refers to the potential mobility in a given landscape and takes into consideration elevation change across a landscape, human interference to movement (Milind, 2004).However, Kathleen Wilson investigated the relationship of tribal people with the landscape and highlighted the complex link between social aspects of place, land and health care.

The Access to healthcare is a norm in most of the developed countries and some developing countries like India. It is an important component in the overall healthcare system and has a direct impact on the burden of disease that encumbers health conditions. Access to health services can arise due to one or different combinations of these four barrier types. In case of physical barrier factors explaining health inequity are landscape terrain, climatic conditions and environmental factors issues which add difficulties in geographical distance. Hence accessibility to health service for these tribal people becomes one of the major problems in Nilgiri district. The geographic distance is important in a large country like India with limited means of communication (Milind Deogaonkar, 2004).

The tribes usually live in low standard accommodation and under less favourable living conditions and health (Baarnhielm 2000) .Poor transportation facilities and physical conditions appear to be the most significant obstacle for tribes in remote areas to access the healthcare centre. In Nilgiri district the utilization of health services is mostly influence by the factors such as climate, forest cover, slope, road networks, drainage and river.

Individual with SCD are at risk for unexpected, intermittent and life threatening complications (i.e pain, joint necrosis and major organ damage). Furthermore, disparities in quality of care are pervasive, especially for ethnic minorities, people of lower socioeconomic status and those residing in remote geographic regions (Report U.S AID, 2009 ) .It is well known that availability and distribution of health care resources in 
remote areas are scarce (Bertakis,2000).Several barriers may impede the management of patients with sickle cell disease.

\subsection{Geographical and Environmental factors as barriers in health access}

Most of the tribes in Nilgiri district are living in forest enclosures and are exposed to a variety of geographic and climatic barriers such as mountainous terrain, large bodies of water, travelling conditions or extreme cold that may prevent them from accessing their usual source of health care. Areas characterised by steep uneven terrain are more problematic and take longer time to navigate than the flat surface. Continuous heavy rains in Nilgiri hills can lead to numerous landslides and cause extensive damage resulting in uprooted trees that can block the road and become impassable to vehicles. Vegetation also affects access; dense vegetation poses difficulty in allowing direct routes to the health centre. The tribes with SCD suffer from pain crisis which can worsen the pain during the rainy reason and may require timely treatment. Hence, the harsh climate along with poor infrastructure can make it challenging for medical services.

The climatic condition such as rainfall may also hinder the access to the health care system in the Nilgiri district. The district usually receives rain both during southwest and northeast monsoon. The average annual rainfall is recorded as $1800-2000 \mathrm{~mm}$. The continuous heavy rains in Nilgiri hills can lead to numerous landslides causing terrain instability. Hence, transport is drastically affected and accessibility to healthcare is a major problem to these tribes. Many roads become impassable to vehicles and this becomes a challenge to medical services. The tribes with SCD suffer from pain crises which can worsen the pain during the rainy season and may need timely treatment. The wild animals in the dense forest area can also limit their access health care when the painful crisis arises.

\subsection{Distance}

The outcome of any disease is influenced by delay in decisions to seek healthcare, timely arrival at appropriate and diagnostic and treatment services. The utilization of health facilities diminishes with distance (Al-Taiar, Noor AM, Feikin DR, Muller, Stock R) and the quality of transportation and road conditions (EOC Survey). Studies have shown that a major factor in the utilization of health services is travel time and defined travel times that exceed 30 minutes are unacceptable (Bertakis KD).

\subsection{Study area}

The Nilgiri district is one of the smallest district of Tamil Nadu. The district is hill area of 2549.0 sq.kms located between $11^{\circ} 10^{\prime}$ and $11^{\circ} 30^{\prime} \mathrm{N}$ latitude, between $76^{\circ} 25^{\prime}$ and $77^{\circ} 00^{\prime} \mathrm{E}$ longitude at the junction of Eastern and the Western Ghats. Physiographically the district is uneven and undulating terrain owing to hilly terrain which is surrounded by hard boundaries in the form of large reserve forest, water body and commercial farmlands like tea plantations. There are 29 Primary health centres (PHCs) in Nilgiris district in which two health centres are affording treatment for the tribes affected with sickle cell disease.

\subsection{Preparation of database and analysis in the GIS}

This study includes both trait and disease cases of Sickle cell anemia between 1997 to 2012 (n 2867) which was drawn from AHWINI (Association for health welfare in the Nilgiris) and CTRD (Centre for Tribal Research Development) and NAWA (Nilgiris Adivasi Welfare Association). The health care and SCD cases locations were geo-coded and generated as point layer. A number of input data sets were required to support the application of the inequity study. The following parameters are used as data sets.

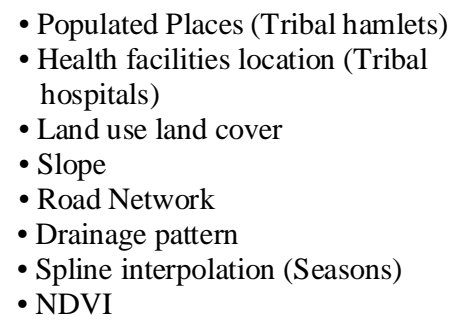

The SCD populated hamlets and health facility locations were geo coded and generated as point layers. GIS vector layers such as administrative boundaries, road networks and drainage have been extracted from toposheets at the scale of 1:50,000 using ArcGIS 9.3. Slope layer is derived from Shuttle Radar Telemetry Mission (SRTM DEM 2009) elevation data. A percent slope surface was created with spatial analysis toolset. The slope surface was reclassified and given as nearly plain, gentle slope, moderate slope, steep slope and very steep slope. The climate data were imported into ArcGIS for spatial data analysis .Spline map was created using interpolation technique for dry and wet season. The Indian Remote Sensing Satellite (1RS-1D) digital data of LISS-III sensor, which provide a resolution of 23.25 meters in multispectral mode, was utilized in the study were derived from Bhuvan for the year 2009. Digital Image Processing (DIP) was done using Erdas Imagine 9.2 software to prepare land use land cover maps. Average speeds for vehicle across different land cover types were estimated based on Nelson 2000 and Toxopeus 1996. The NDVI base data of remote sensing data sets of Landsat 8 was performed to analyse the vegetation cover in Nilgiri district.

\subsection{Terrain Stability Mapping Method}

Terrain stability mapping involves the subdivision of landscape into geomorphic units (i.e., terrain features) based on the criteria established for this study. For the present study, terrain mapping techniques were used to delineate areas with terrain instability due to rainfall, slope, land use land cover, vegetation pattern, drainage and road network. All layers were converted to raster stability analysis .The raster layers were overlayed and Weightage was given to each theme depending on the severity of the factors related to terrain difficulty occurrences and a GIS algorithm was derived to calculate the cut-off values (Table 1). The Final output was categorised as stable, moderately stable, quasi-stable, lower threshold and 
upper threshold. Further cost distance analysis was carried out for accessibility model.

Table.1 Five default stability index classifications

\begin{tabular}{|l|l|}
\hline Classification & $\begin{array}{l}\text { Stability Index } \\
\text { Values (SI) }\end{array}$ \\
\hline Stable & SI $>1.5$ \\
\hline Moderately Stable & $1.5>$ SI $>1.25$ \\
\hline Quasi-stable & $1.25>$ SI $>1.0$ \\
\hline Lower Threshold & $1.0>$ SI $>0.5$ \\
\hline Upper Threshold & $0.5>$ SI $>0.0$ \\
\hline
\end{tabular}

Source Montgomery and D ietrich 1994.

\subsection{Accessibility surface model}

For the present study accessibility surfaces were generated using the cost-distance function in the ArcGIS environment. Euclidean distances between each road network and the nearest public health facilities were computed. Secondly, a cost-distance analysis was carried out for dry and wet season with terrain stability output as friction surface (Figure 2.1) This cost distance function is an isotropic algorithm, meaning that each cell within the friction surface used as the input grid to the function contains a single value representing the cost of movement across that location (cell) in any direction. The friction layers were reclassified so that the value of each cell is represented as speed in minute using raster calculator. The friction components were then merged into a single friction surface by assigning weightage of influence and the costdistance function was applied to calculate time to access the specified health centre (Figure 2.2). The shortest path analysis was used to identify the shortest distance route from tribal location to health care based on terrain difficulties. Network analyst tool of ArcGIS uses Dijkstra's algorithm was used to identify the shortest path (Dijkstra, 2014).

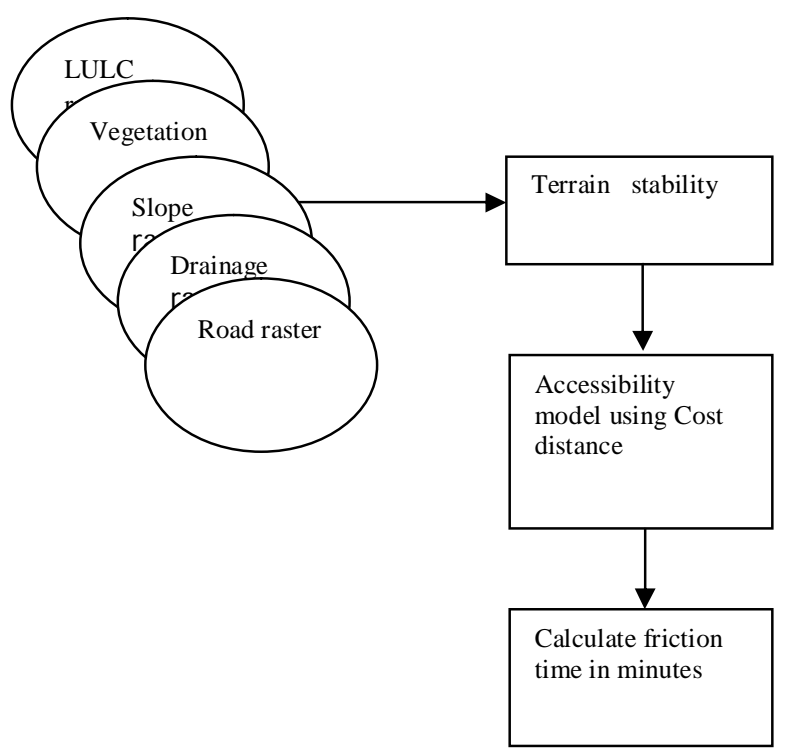

Figure 2.1 Flow chart showing accessibility model

\subsection{Results}

Population density was considered an important attribute because interventions to improve healthcare access need to be in areas that can impact the largest number at-risk community members. The population density of each revenue village was calculated based on the population by the total geographical area of the village and presented as (Figure 3.1). The population density was recorded in Allimoyar with 522.4 sq.kms followed by Kallampalayam, Erumad and Srimadural being the most densely-populated neighborhoods and Nedugula, Bikkatti, Mulligur, Naduvattam, Tuneri and Thummanatti have low population density.

Figure 3.1 Population Density and prevalent of SCD cases of Nilgiri District of Tamil Nadu

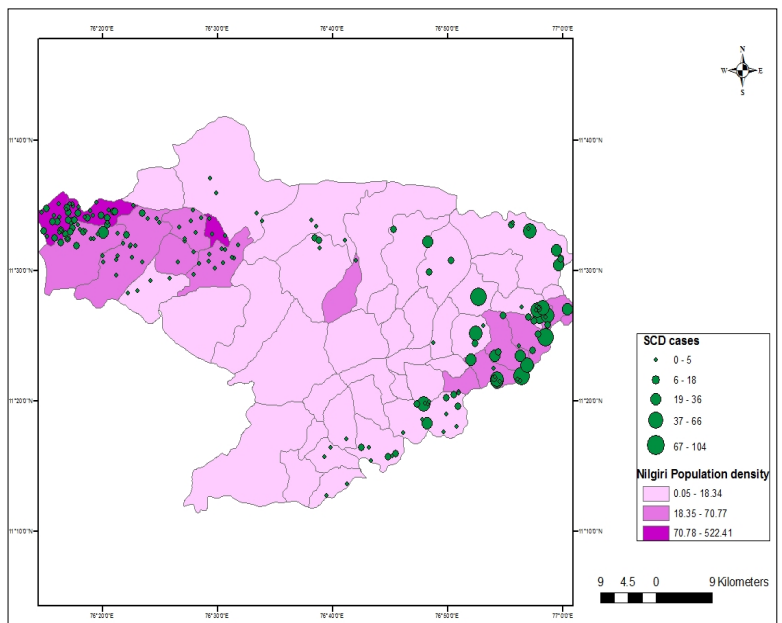

\subsection{Terrain stability of Nilgiri district}

From the resultant map, it was observed that the terrain instability area covered north eastern region and western parts of the district including Gudalur, Pandalur some regions of Ooty and Kotagiri district (figure 3.2). These regions are covered with dense forest and with highest rainfall with maximum of 116.1 to $112.3 \mathrm{~mm}$.Stable zones were observed in few parts of Kundah taluk and moderate covers almost Coonoor region for dry season. Whereas during wet season northern part of Gudalur taluk is observed as high instable .It is observed that a maximum of 976.7 to $460.9 \mathrm{~mm}$ rainfall was recorded in Gudalur .This is observed to be the major cause for instability along with slope and land use land cover figure 3.3. Hence the instability of terrain feature play major role in inaccessibility to health care. 


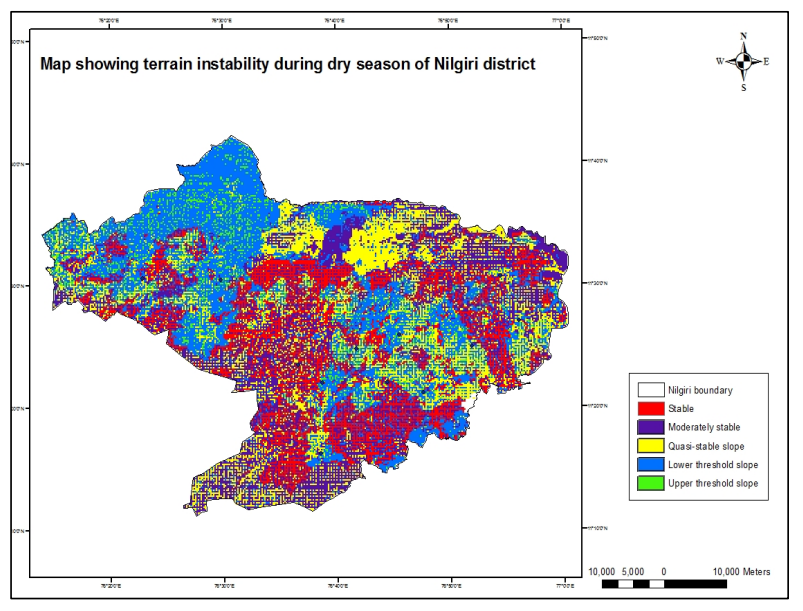

Figure 3.2 Map of terrain instability during dry season for Nilgiri district of Tamilnadu

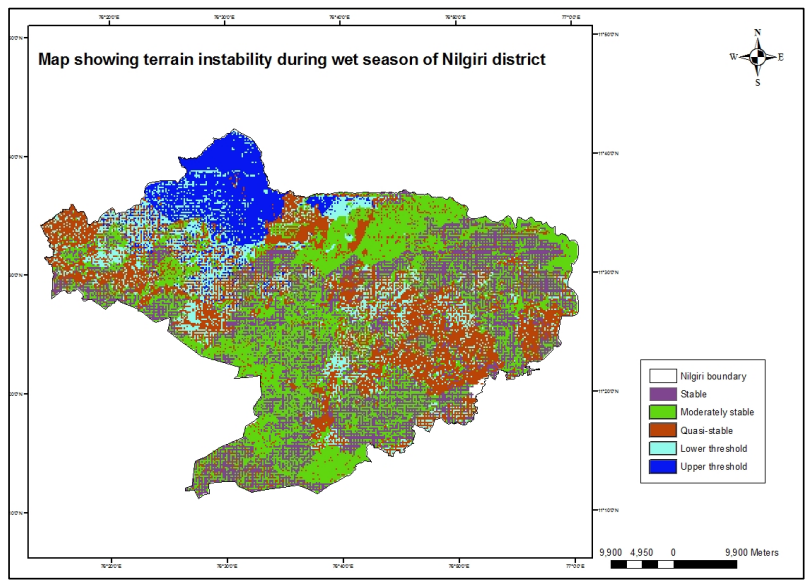

Figure 3.3 Map of terrain instability during wet season for Nilgiri district of Tamilnadu

\subsection{Travel time distribution using Accessibility modeling}

\subsubsection{Euclidean Distance model for road network}

The results of the travelling cost in terms of time was created using the accessibility surface model of the Nilgiri region, based on Euclidean and Cost distance analysis. The results of Euclidean distance is shown in (Figure 3.3) .It appears that most of district is well covered with roads except for boundary regions were they are covered with reserve forest .The analysis shows that the cost is fairly even and very few hamlets comes under inaccessible to road network. From the result it is observed that an average of 40 minutes is dedicated to reach the health centres through road network.It was also inferred that there were no proper road facilities to access the primary care in northern and north eastern part were the region is covered with dense forest, this may be one of the reason for long travel time. Euclidean distances can overestimate the tribal population that is within 1-hour of a health facility using transport network, elevation and other natural barriers that can provide more accurate estimates (Alun, 1998) as used here with cost distance analysis.

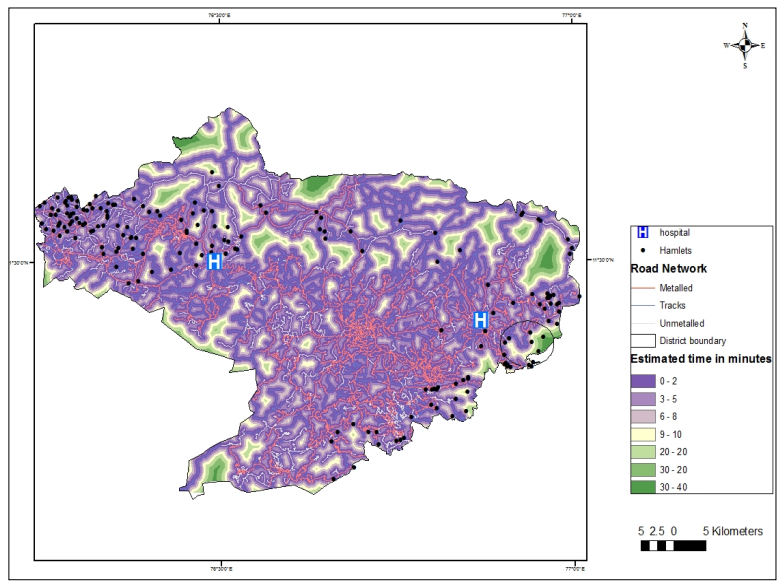

Figure 3.3 Travel time to health centres by Euclidean Distance model

\subsubsection{Accessibility model for dry and wet season}

Accessibility to health facilities during both the dry and wet season is shown in Figure3.5. During the dry season, accessibility is faster than the wet season because of vehicular travel to health centre .But during wet season the access to health centre is reduced due to impassable of road network caused by terrain instability. The most inaccessible regions were west of Nilgiri district for both dry and wet season.

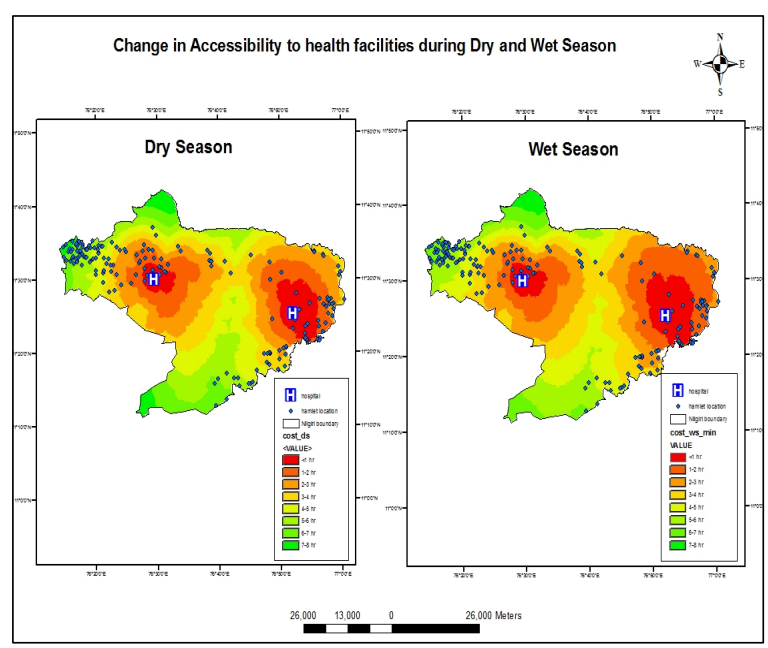

Figure 3.4 Changes in accessibility to health facilities during dry and wet seasons by travel

The total number of hamlets in different accessibility time for dry and wet season is shown in Table 2. During the dry season $12 \%$ of the hamlets were within 1-hour accessibility of a health facility, which was reduced to $9 \%$ during the wet season. It is observed that the accessibility rate was 
comparatively reduced from dry season to wet season for time interval (1 to 8 hours) in the study area. Furthermore, inaccessibility to these hamlets during the wet season is due to terrain difficulty induced by many other external factors like contour slope, land use land cover, road network and drainage pattern.

Table 2 Total number of hamlets in different accessibility time to health facilities during dry and wet season

\begin{tabular}{|c|c|c|}
\hline \multirow{2}{*}{ Hours } & \multicolumn{2}{|c|}{ Total number of hamlets } \\
\cline { 2 - 3 } & Dry Season & Wet Season \\
\hline$<1$ & $30(12 \%)$ & $23(9 \%)$ \\
\hline $1-2$ & $28(10 \%)$ & $24(9.4 \%)$ \\
\hline $2-3$ & $29(11 \%)$ & $26(10 \%)$ \\
\hline $3-4$ & $30(12 \%)$ & $22(8.6 \%)$ \\
\hline $4-5$ & $14(5.4 \%)$ & $21(8.2 \%)$ \\
\hline $5-6$ & $23(9 \%)$ & $23(9 \%)$ \\
\hline $6-7$ & $29(11 \%)$ & $26(10 \%)$ \\
\hline $7-8$ & $5(1.9 \%)$ & 0 \\
\hline
\end{tabular}

\subsubsection{Accessibility model without season influence}

The cost-distance function estimates, for each cell, the time required to reach the nearest destination is health centre. Travel time is calculated over a friction surface that takes into account the road network, land cover and slope without season. The Figures 3.7 illustrates that accessibility has evidently changed over different terrain surfaces of the district which in turn impacts the tribal population in accessing the health care. The population with least access to health care can be determined by overlaying the tribal settlements on the accessibility. From the output it is observed that a distinct cluster was identified in the western part of Nilgiri district where access to a health centre was found to take in excess of 8 hours travel time mainly of impedance due to the dense forest highlighted as black ring. The easily accessible hamlets within 1 hour travel time consist of 18 villages. Several settlements that were inaccessible since slope and land use land cover impede the access to health care.

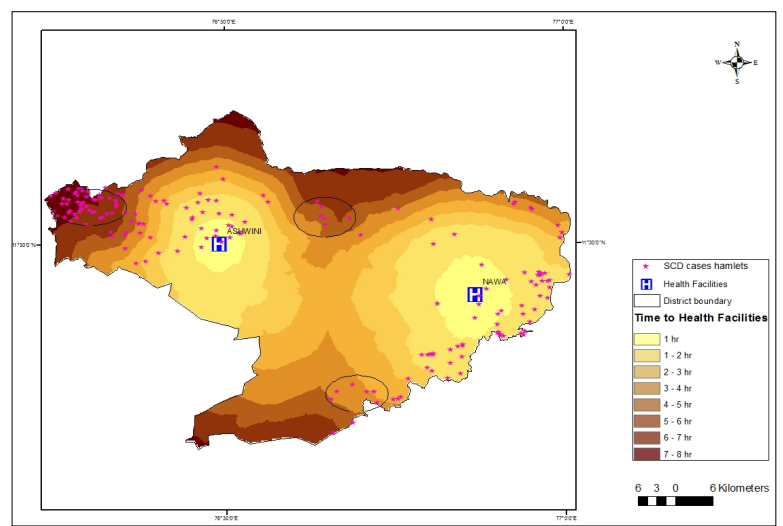

Figure 3.4 Changes in Accessibility to Health Facilities in Nilgiri District of Tamil Nadu
The maximum travel time defined for a patient that requires access to a particular health facility depends upon the severity of his/her condition. In the context of this study, the maximum travel time permitted was established as 1 hour so as to be able to identify the parts of the region where accessibility is worse.

\subsubsection{Shortest path analysis}

Travelling is part of daily life of every people. As the terrain condition changes due to environmental factors, there is a need to find an alternate shortest route for the inaccessible areas. Network analyst tool of ArcGIS Dijkstra's algorithm has been used to find the shortest path. Based on the results of the cost distance the alternate shortest route derived using shortest path analysis. The inaccessible areas were chosen for the present study for alternate route. The total distance from destination to health centre is about $31.3 \mathrm{~km}$ for Erumad region whereas the shortest route shows $23 \mathrm{~km}$ (Figure 3.8) which is $8 \mathrm{~km}$ difference. Similarly from Kadanadu to NAWA it takes around $45 \mathrm{~km}$ which is reduced to $29 \mathrm{~km}$ by alternate route.

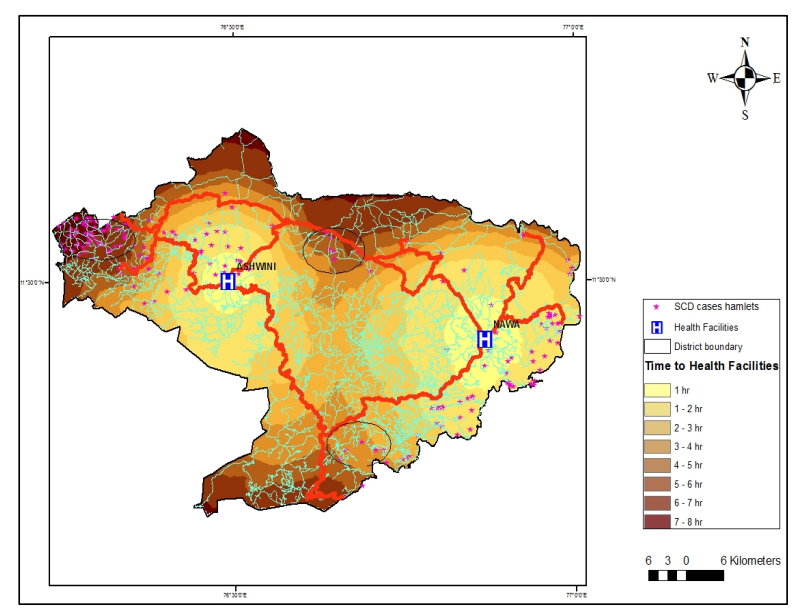

Figure 3.5 Shortest routes for inaccessible areas in Nilgiri district

\subsection{Discussion}

In recent years, it is noticed that there is a burgeoning interest in the geographical and spatial aspects of the analysis of health care systems. Lovett 1992 identified GIS technology as potential valuable adjunct in epidemiology and in the spatial analysis of health care utilization .This study highlights critical areas in Nilgiri district where health services/facilities may need to be improved using travel time estimates eliminating all the barriers to represent access time. The study also highlights the factors that play major in the terrain instability in the study region. The results of the travelling cost in terms of time and distance conveys that central hamlets of the study area are relatively accessible both Euclidean and cost distance analysis as compared to southern and northern villages. It is clearly evident that topography plays a direct control on accessibility to health centres were 
western, northern and southern hamlets shows inaccessible to health centres acting as barriers. Analysis using both Euclidean distance and cost distance using GIS methods of measurement has revealed the tribal people who were able to access road networks were impeded by geographical conditions such as slope and land use pattern as speed reducing factor. Here, we have used a uniquely detailed assembly of spatial data on the population, health service and topographic landscape data, to reconstruct realistic levels of geographical access to health care facilities to these sickle cell disease tribal patients in Nilgiri district.

The study indentified limited accessible zones where can be used to assess placement of new health facilities based on tribes with sickle cell disease and realistic travel time. The findings help us to eliminate the identified barriers and can improve the access to health services across tribal groups. Though AHWINI in Gudalur and NAWA in Kotagiri is however a facility established to monitor the disease cases through mobile outreach in spite of these influencing factors. The health planners aim at developing health policy and services that address geographical and social inequalities in health, and therefore should benefit from evidence-based approaches in health service provision (Milind, 2004).

\subsection{Conclusion}

The study shows that social and geographical inequities in health care use were observed among tribal groups between different geographic areas. The distributions of health services for theses tribes in the Nilgiri regions are limited. The socially underprivileged are unable to access the healthcare due to geographical barriers, social and gender related issues. Based on the accessibility map analysis for different seasons, it can be observed that factors such as slope, Rainfall and land use land cover factors act as hindrances in accessing the facilities. Limited road facilities are available to high incidences areas. They have to travel for long distance in order to avail the medication in the service centre. Hence alternate route to reach the health centres has been studied. Addressing the difference in the travel burden based on age and gender will require health planners for resource allocation.

\subsection{References}

Acharya LB, Cleland J: Maternal and child health services in rural Nepal: does access or quality matter more? Health Policy Plan 2000, 15: 223-29.

Al-Taiar A, Clark A, Longenecker JC, Whitty CJM: Physical accessibility and utilization of health services in Yemen. Int $J$ Health Geogr 2010, 9:38.

Baarnhielm S, Ekblad S: Turkish migrant women encountering health care in Stockholm: a qualitative study of somatisation and illness meaning. Cult Med Psychiatry 2000, 24: 431-452.

Bertakis KD, Azari R, Helms LJ, Callahan EJ, Robbins JA: Gender differences in the utilization of health care services. $J$ Fam Pract 2000, 49:147-152. BMC Health Serv Res 2007, 7:40-52.
Bosanac E, Parkinson R, Hall D: Geographical access to hospital care: a 30-minute travel time standard. Medical Care, 1976, 14(Suppl 7):616-624.

Dijkstra's algorithm sited on $20^{\text {th }}$ march 2014 http://en.wikipedia.org/wiki/dijkstra's algorithm.

Feikin DR, Nguyen LM, Adazu K, Ombok M, Audi A, Slutsker L, Lindblade KA: The impact of distance of residence from a peripheral health facility on pediatric health utilisation in rural western Kenya. Trop Med Int Health 2009, 14(Suppl 1):54-61.Francis 1992. London.

Hartley AJ, Nelson A, Mayaux P and Gregoire JM: The assessment of African Protected Areas - A characterisation of biodiversity value, ecosystems and threats, to inform the effective allocation of conservation funding. JRC Scientific and Technical Reports 2007. Institute for Environment and Sustainability, European Commission Joint Research Centre. pp. 77.

Lavy V, Germain JM, World Bank. Quality and cost in health care choice in developing countries. 1994. Washington, DC: World Bank.

Lovett AA: Geographical Information 1992/3.The Year book of the association for geographical information. Taylor and Milind Deogaonkar M: Socio-economic inequality and its effect on healthcare delivery in India. Electronic journal of Sociology 2004.

Muller I, Smith T, Mellor S, Rare L, Genton B: The effect of distance from home on attendance at a small rural health centre in Papua New Guinea. Int J Epidemiol 1998, 27(Suppl 5):878-884.

Nelson A: Accessibility, transport and travel time information. In CIAT Hillsides Project Report. Cali: International Center for Tropical Agriculture (CIAT); 2000.

Nelson, A: African Population Database Documentation. 2004.

Noor AM, Zurovac D, Hay SI, Ochola SA, Snow RW: Defining equity in physical access to clinical services using geographical information systems as part of malaria planning and monitoring in Kenya. Trop Med Int Health 2003, 8(Suppl 10):917-926.

Pozzi F, Robinson T: Accessibility Mapping in the Horn of Africa: Applications for Livestock Policy. In Working Paper No 11-08.: IGAD LPI; 2008:35.

Rogers AE, FlowersJ, PencheonD. Improving access needs a whole systems approach and will be important in averting crises in the millennium winter. British Medical Journal 1999, $319,7214,866-867$.

Stock R: Distance and the Utilization of Health Facilities in Rural Nigeria. Soc Sci Med 1983, 17(Suppl 9):563-570. 
The International Archives of the Photogrammetry, Remote Sensing and Spatial Information Sciences, Volume XL-8, 2014 ISPRS Technical Commission VIII Symposium, 09 - 12 December 2014, Hyderabad, India

Technical Report. Using Geographic Information System Tools to Address Disparities in Access and to Family Planning Services Commodities in Latin America and the Caribbean.U.S Agency for International Development.2009.
You, L. and Chamberlin, J. Spatial analysis of sustainable livelihood enterprises of Uganda cotton production. Washington DC: International Food Policy Research Institute (IFPRI), Environment and Production Technology Division (EPTD) Discussion Paper No. 121.2004 